\title{
Experimental consideration on evaporation efficiency $\beta$ of unsaturated sandy soil surface
}

\author{
Kazunari Sako ${ }^{\text {i) }}$, Motoki Moriiwa ${ }^{\text {ii) }}$ and Tomoaki Satomi ${ }^{\text {iii) }}$ \\ i) Associate Professor, Dept. of Ocean Civil Engineering, Kagoshima University, 1-21-40, Korimoto, Kagoshima 890-0065, Japan. \\ ii) Graduate student, Dept. of Ocean Civil Engineering, Kagoshima University, 1-21-40, Korimoto, Kagoshima 890-0065, Japan. \\ iii) Assistant Professor, Graduate School of Environmental Studies, Tohoku University, 6-6-20, Aobaku, Sendai, Miyagi 980-8579, Japan.
}

\begin{abstract}
The balk transfer method is one of the evaporation estimation methods. The amount of evaporated water from bare ground surfaces can be estimated from the general meteorological data using the method. A moisture exchange speed, $g_{\mathrm{a}}$, and evaporation efficiency, $\beta$ are important parameters of the method, and they are influenced by volumetric water content in unsaturated soil. The authors have proposed the estimation method of the exchange speed considering the soil thermal capacity, $g_{\mathrm{a}, \text { soil. }}$. In this paper, the evaporation efficiencies are obtained from our proposed procedure, the relationship between volumetric water content and evaporation efficiency of unsaturated sandy soil is discussed based on the experimental results. As the results, the properties of evaporation efficiency depend on volumetric water content are clearly explained.
\end{abstract}

Key words: evaporation, evaporation efficiency, balk transfer method, unsaturated sandy soil, laboratory test

\section{INTRODUCTION}

In Japan, almost real time warning system for rainfall-induced slope failure has been conducted using rainfall intensity indexes. However, there are no estimation methods to decide the deregulation of evacuation. It is important to obtain the amount of evaporation in order to analyze slope stability after rainfall. Slope stability after rainfall will be calculated using real time monitoring data and numerical simulations (unsaturated seepage analysis and slope stability analysis). In this paper, the bulk transfer method (e.g., Kondo, 1994) is employed to estimate the amount of evaporation from bare ground surface. Using the method, the amount of evaporated water from ground surfaces can be estimated from the general meteorological data. A moisture exchange speed, $g_{\mathrm{a}}$, and evaporation efficiency, $\beta$ are important parameters of the bulk transfer method, and $\beta$ is influenced by volumetric water content, $\theta$ in unsaturated bare soil surface (Kondo et al., 1990, Mahfouf and Noihan, 1991).

In this paper, properties on evaporation efficiency of unsaturated bare sandy soil surface will be discussed based on laboratory experiment. Firstly, the outline of the bulk transfer method and the derivation methods of $g_{\mathrm{a}}$ and $\beta$ is shown. Especially, the moisture exchange speed considering the soil thermal capacity, $g_{a, \text { soil }}$ proposed by Satomi et al. (2010) is explained. The derivation method of the relationship between the evaporation efficiency and the volumetric water content of Toyoura sandy soil is also described. Comparing with the experiment results obtained from our proposed method and the experimental formula proposed by Kondo et al. (1990), the properties on the evaporation efficiency of unsaturated bare sandy soil surface are taken into account.

\section{ESTIMATION METHOD OF EVAPORATION}

\subsection{Outline of bulk transfer method}

The estimation method of evaporation using the bulk transfer method is expressed as the following equation.

$$
\begin{aligned}
& E=\rho \cdot g_{a} \cdot \beta \cdot\left(q_{\text {sat }}-q_{a}\right) \\
& g_{a}=C_{H} \cdot U
\end{aligned}
$$

\begin{tabular}{|c|c|}
\hline parameters & obsabation data \\
\hline \multirow{4}{*}{$\begin{array}{l}\text { air density } \\
\rho\left[\mathrm{kg} / \mathrm{m}^{3}\right]\end{array}$} & $P:$ atmospheric pressure $[\mathrm{hPa}]$ \\
\hline & $T_{\mathrm{a}}$ : temperature $\left[{ }^{\circ} \mathrm{C}\right]$ \\
\hline & $T_{\mathrm{s}}$ : ground surface temperature $\left[{ }^{\circ} \mathrm{C}\right]$ \\
\hline & $H_{\mathrm{u}}:$ relative humidity [\%] \\
\hline \multirow{2}{*}{$\begin{array}{c}\text { saturation sepcific } \\
\text { humidity: } q_{\text {sat }}[\mathrm{kg} / \mathrm{kg}]\end{array}$} & $P:$ atmospheric pressure $[\mathrm{hPa}]$ \\
\hline & $T_{\mathrm{s}}$ : ground surface temperature $\left[{ }^{\circ} \mathrm{C}\right]$ \\
\hline \multirow{3}{*}{$\begin{array}{c}\text { specific humidity } \\
\text { of the air } \\
q_{\text {a }}[\mathrm{kg} / \mathrm{kg}] \\
\end{array}$} & $P:$ atmospheric pressure $[\mathrm{hPa}]$ \\
\hline & $T_{\mathrm{a}}$ : temperature $\left[{ }^{\circ} \mathrm{C}\right]$ \\
\hline & $H_{\mathrm{u}}$ : relative humidity [\%] \\
\hline exchage speed & \multirow{2}{*}{$\begin{array}{l}\text { obtined from } \\
\text { the laboratory experiments }\end{array}$} \\
\hline evaporation efficiency & \\
\hline
\end{tabular}

Table 1. Parameters of the bulk transfer method 
Where, $E$ is the evaporation per unit area $\left[\mathrm{kg} \mathrm{m}^{-2} \mathrm{~s}^{-1}\right], C_{\mathrm{H}}$ is the bulk transfer coefficient for sensible heat flux [-], $U$ is wind speed $\left[\mathrm{m} \mathrm{s}^{-1}\right]$. The other parameters are shown in Table 1. The almost parameters of the bulk transfer method can be derived from the general meteorological data. However, the exchange speed and evaporation efficiency have to derive from the laboratory experiments. The exchange speed is defined as the speed that the air around the ground is exchanged for the air in the atmosphere. The evaporation efficiency ranges 0 to 1 depend on the soil moisture (e.g. $\beta=0$ at the dry condition, $\beta=1$ at the saturated condition).

\subsection{Derivation procedure of the relationship between $\boldsymbol{\theta}$ and $\boldsymbol{\beta}$}

Figure 1 shows the flow chart of the derivation of the relationship between the volumetric water content, $\theta$, and the evaporation efficiency, $\beta(\theta-\beta$ relation). The soil tank experiment was established by Kondo et al. (1990). In Kondo’s procedure (Kondo et al. 1992, 1997), the exchange speed, $g_{\mathrm{a}}$ is estimated using the in-situ monitoring data, the equation of $g_{\mathrm{a}}$ is expressed as the following.

$$
g_{a}=b\left(T_{s}-T_{a}\right)^{1 / 3}
$$

Where, $b$ is the influence coefficient on vegetation. Although to obtain the exchange speed, $g_{a}$, from the metrological data is important in order to measure the amount of evaporated water from the in-situ ground surface, the $g_{\text {a }}$ obtained from the meteorological data varies widely. The procedures (water experiment) of the derivation of the exchange speed from water surface, $g_{\text {a,water, and the consideration of the volumetric thermal }}$ capacity are add to the flow chart in our method (Satomi, 2010). In our proposed procedure, the

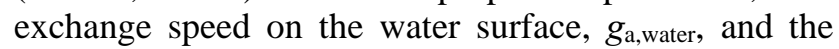
exchange speed on the soil surface, $g_{a, s o i l}$, are obtained from the water tank experiment and the soil tank experiment. Using the experiment results of the evaporation from water surface, $E$, and the

Table 2. density and specific heat of each material

\begin{tabular}{|c|c|c|}
\hline & dencity & specific heat \\
\cline { 2 - 3 } & $\rho\left[\mathrm{kg} / \mathrm{m}^{3}\right]$ & $c[\mathrm{~kJ} /(\mathrm{kg} \cdot \mathrm{K})]$ \\
\hline soil particle & 2,652 & 0.84 \\
\hline water & 1,000 & 4.18 \\
\hline air & 1.293 & 1.000 \\
\hline
\end{tabular}

meteorological data, the exchange speed on the water, $g_{\text {a,water, }}$ is derived. The evaporation efficiency is equal to $1(\beta=1.0)$ on the water surface. It seems that the exchange speed on the soil surface is influenced by the thermal capacity of the soil. The volumetric thermal capacity of the soil, $C_{\text {soil }}$, is expressed as the following. The parameters of each material are listed in Table 2.

$$
C_{\text {soil }}=\frac{V_{s}}{V} \rho_{s} c_{s}+\frac{V_{w}}{V} \rho_{w} c_{w}+\frac{V_{a}}{V} \rho_{a} c_{a}
$$

Where, $V$ is Volume of specimen $\left[\mathrm{m}^{3}\right], \rho_{\mathrm{s}}$ is soil particle density $\left[\mathrm{kg} \mathrm{m}^{-3}\right], \rho_{\mathrm{w}}$ is water density $\left[\mathrm{kg} \mathrm{m}^{-3}\right], \rho_{\mathrm{a}}$ is air density $\left[\mathrm{kg} \mathrm{m}^{-3}\right], c_{\mathrm{s}}$ is specific heat of the soil particle $\left[\mathrm{kJ} \mathrm{kg}^{-1} \mathrm{~K}^{-1}\right], c_{\mathrm{w}}$ is specific heat of the water [ $\mathrm{kJ} \mathrm{kg}^{-1}$ $\mathrm{K}^{-1}$ ], $c_{\mathrm{a}}$ is specific heat of the air $\left[\mathrm{kJ} \mathrm{kg}^{-1} \mathrm{~K}^{-1}\right.$.

It is found from Table 2 and Eq.(4) that the volumetric thermal capacity of the saturated soil is larger than that of the dry soil under the same quantity of heat. Using the volumetric thermal capacity of the soil, $C_{\text {soil }}$, and that of water, $C_{\text {water, }}$ the exchange speed on the ground surface, $g_{\text {a,soil, }}$ can be expressed as the hollowing equation.

$$
g_{a, \text { soil }}=\frac{C_{\text {water }}}{C_{\text {soil }}} g_{a, \text { water }}
$$

In this paper, the $\theta-\beta$ relation are obtained from experiments using $g_{\mathrm{a} \text {,soil }}$ expressed by Eq.(5).

\section{WATER AND SOIL TANK EXPERIMENTS}

\subsection{Outline of the experiments}

Figure 2 shows the schema of the experiments devices. The devices were composed of the meteorological device, soil tank, and water tank. Toyoura sand was used as the experimental sample. The shape of the tanks was a circular cylinder. The inside 
diameter was $15.5 \mathrm{~cm}$, the depth of the tanks was $2 \mathrm{~cm}$. Void ratio of soil specimens was set to 0.785 , the soil specimens were compacted every $1 \mathrm{~cm}$. The circumference of the tanks was covered by the insulation. The thermometers were set on the soil surface and at the depth of $1 \mathrm{~cm}$ in the soil tank. Then, the moisture sensor was also laid at the depth of $1 \mathrm{~cm}$ in the soil tank. A thermometer was set on the water surface in the water tank. The electric balances were used to measure the amount of evaporated water from the soil surface and water surface. The maximum of the electric balance is $3,200 \mathrm{~g}$, the standard deviation of the electric balance is $0.01 \mathrm{~g}$.

Table 3 shows the initial conditions of experiments. These experiments were conducted under the different initial conditions (the degree of saturation of soil, $S_{\mathrm{r}}=$ $10,20,40,60,80 \%)$. The measurement data were recorded every 15 minutes. Each experiment was finished in 1,200 minutes. In order to make the condition of natural convection $\left(T_{\mathrm{s}}-T_{\mathrm{a}} \geqq 0.5\right)$, the desk lamp (200W) were used to heat the surfaces of soil and water up.

\subsection{Experimental results}

Figure 3 shows one of the experimental results (initial condition: $S_{\mathrm{r}}=20 \%$ ). The change in each temperature [deg.], volumetric water content measured by moisture sensor [-], and the amount of evaporation [g $\left.(15 \mathrm{~min})^{-1}\right]$ with time are shown in Fig.3. The amount of evaporation from the soil surface is larger than that from the water surface during the early stages of the experiment. Then, the amount of evaporation from the soil surface was decreased with the decrease in the volumetric water content of the soil surface. It can be seen that the tendency is caused by the decrease of the evaporation efficiency. The volumetric water content showed the negative values from 500 minutes. It seems that the moisture sensor could not measure the volumetric water content of dry sand.

\section{RELTIONSHIP BETWEEN $\theta$ AND $\beta$}

Figure 4 shows the relationship between the volumetric water content and evaporation efficiency $(\theta$ - $\beta$ relation) obtained from the experiments based on the flow chart shown in Fig.1. It is found from Fig.4 that the data vary widely. It seems that the values of electric balances changed widely because the moisture sensors set in the soil tank moved. The authors conducted the experiments removed the moisture sensors, and the results are shown in Fig.5. The volumetric water content was estimated from the data of the electric balances. It is found from Fig.5 that the experimental results are improved.

The line drawn in Fig.4 and Fig.5 derived using the experimental formula of the $\theta$ and $\beta$ relation for sandy soil proposed by Kondo et al. (1994). It is found from Fig.5 that the evaporation efficiency obtained from the

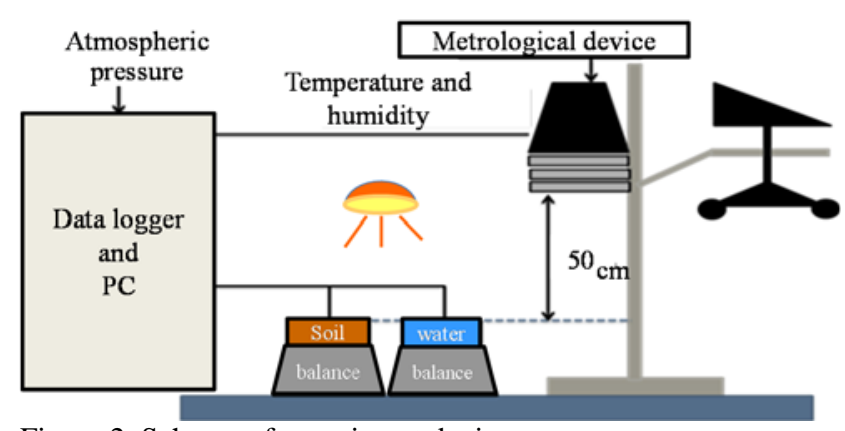

Figure 2. Schema of experiment devices

Table 3. Initial condition of the experiments.

\begin{tabular}{|c|c|c|c|}
\hline \multirow{4}{*}{$\begin{array}{c}\text { Case of } \\
\text { experiments }\end{array}$} & $\begin{array}{c}\text { initial degree of } \\
\text { saturation } S_{\mathrm{r}}[\%]\end{array}$ & $\begin{array}{c}\text { volumetric } \\
\text { water } \\
\text { content } \theta\end{array}$ & $\begin{array}{c}\text { number of times } \\
\text { conductied } \\
\text { experiments }\end{array}$ \\
\cline { 2 - 4 } & 10 & 0.044 & 3 \\
\cline { 2 - 4 } & 20 & 0.088 & 4 \\
\cline { 2 - 4 } & 40 & 0.176 & 3 \\
\hline & 60 & 0.264 & 6 \\
\hline
\end{tabular}
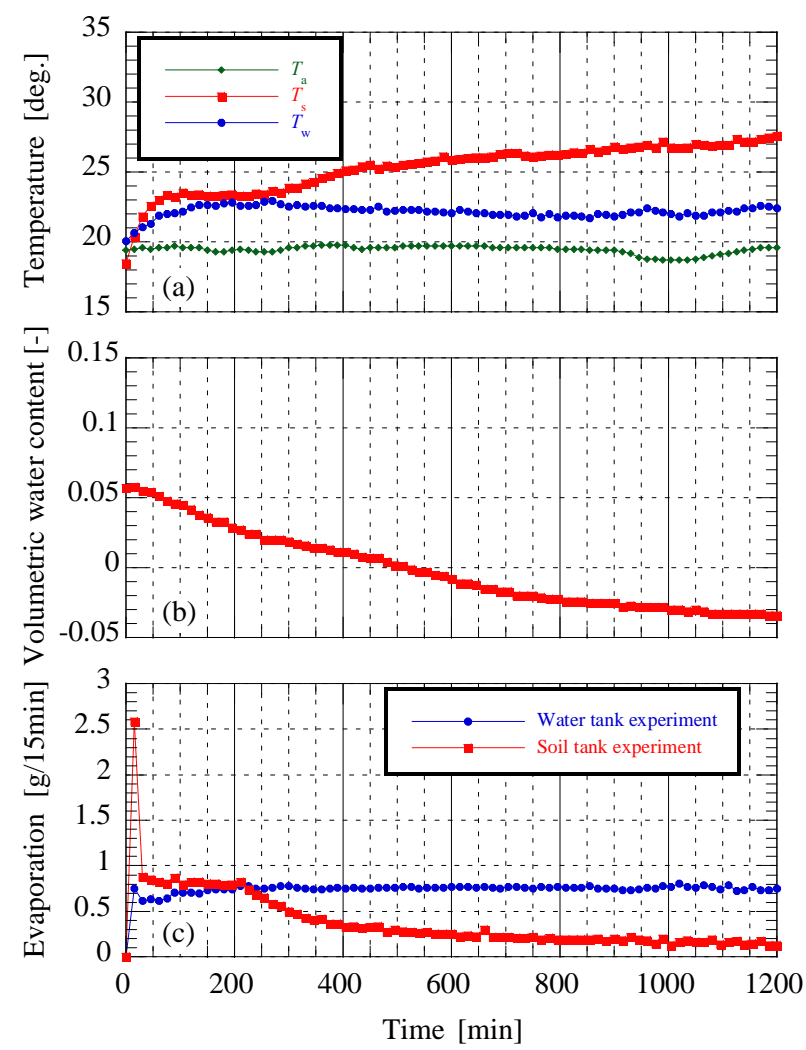

Figure 3. Experimental results ( $S_{\mathrm{r}}=20 \%$ )

experimental results is smaller than the results of Kondo's formula. It seems that the difference of the tendency was caused, because the experimental results were obtained using the exchange speed considered the volumetric thermal capacity of soil, $g_{\text {a,soil }}$.

Figure 6 shows the experimental results of the $\theta$ and $\beta$ relation using the exchange speed on the water surface, $g_{a \text { a,water. The tendency of the experimental }}$ results is almost same to the results of Kondo's formula. 
However, the gradient of the $\theta$ and $\beta$ relation obtained from the experiments $\mathrm{d} / \mathrm{d} \theta$ is larger than the results of Kondo's formula. It seems that the difference of the gradient of the $\theta$ and $\beta$ relation is caused because the effect of soil density (void ratio) is not considered in the Kondo's formula. It is also found from Fig.6 that the evaporation efficiency shows more than 1.0 in some experiment results (I in Fig.6). The range of I in Fig.6 is the results of the early stage of experiment. The amount of evaporation from the soil surface is larger than the amount of evaporation from the water surface during the early stage of experiments as shown in Fig.3(c). $\beta$ is more than 1.0. The range of II in Fig.6 is generated when the amount of evaporation from the soil surface is same to the amount of evaporation from the water surface. $\beta$ shows about 1.0. In the range of III in Fig.6, the evaporation efficiency is decreased with the decrease in the volumetric water content of soil surface.

\section{CONCLUSIONS}

The experiments to obtain the $\theta$ and $\beta$ relation for Toyoura sandy soil were conducted by the use of our proposed derivation procedure, and the experiment results were discussed. Using our procedure, the properties of evaporation efficiency obtained from the experiment can be clearly explained. It was found that the $\theta$ and $\beta$ relation is influenced by void ration of soil. The authors will make a numerical model that the $\theta$ and $\beta$ relation can be estimated by the use of basic soil properties (e.g. grain size distribution and void ratio).

\section{ACKNOWLEDGEMENTS}

The work was supported by Grant-in-Aid for Young Scientists (A) Number 24686056.

\section{REFERENCES}

1) Kondo, J. (1994): Meteorology of the water environment , water and heat balance of the earth -, Asakura Co. Ltd., 194-198.(in Japanese)

2) Kondo, J. and Ishida S. (1997): Sensible heat flux from the earth's surface under natural convective conditions, J. Appl. Meteor., 54, 501.

3) Kondo, J.,Saigusa, N. and Sato, T. (1990): A parameterization of evaporation from bare soil surface. $J$. Appl. Meteorol., 29, 385-89

4) Kondo, J. and Watanabe T. (1992): Studies on the bulk transfer coefficients over a vegetated surface with a multilayer energy budget model, J. the Atmospheric Sciences, 2183-2199.

5) Mahfouf, J. and Noilhan, J. (1991): Comparative study of various formulations of evaporation for bare soil using in situ data, J. Appl. Meteorol., 30, 1354-1365.

6) Satomi, T. Sako, K. Yoshidome, H. and Fukagawa R. (2010): Improvement for the estimation method of evaporation using bulk method concerning water content variation of the uppermost soil layer, J. Applied Mechanics, JSCE, 13, 525-534. (in Japanease)

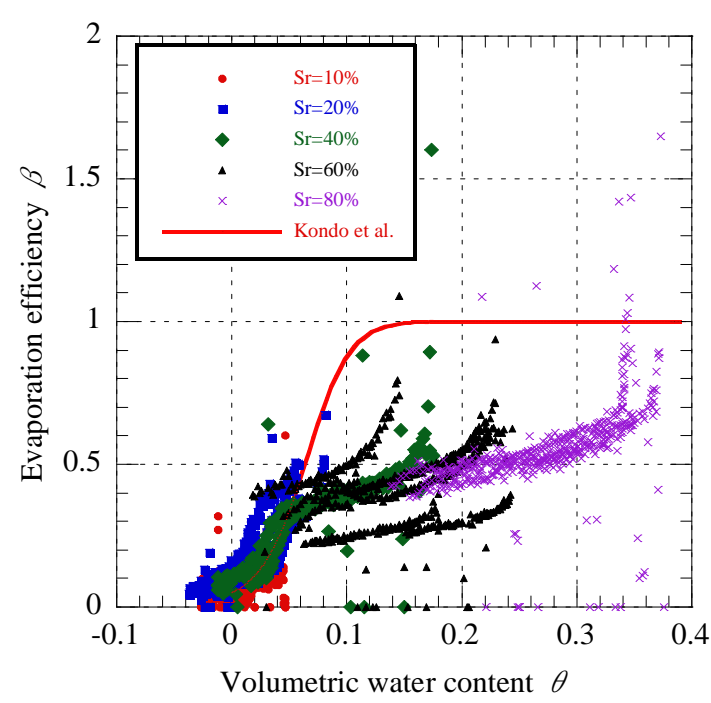

Figure 4. Experimental results of $\theta$ and $\beta$ relation (with the moisture sensors)

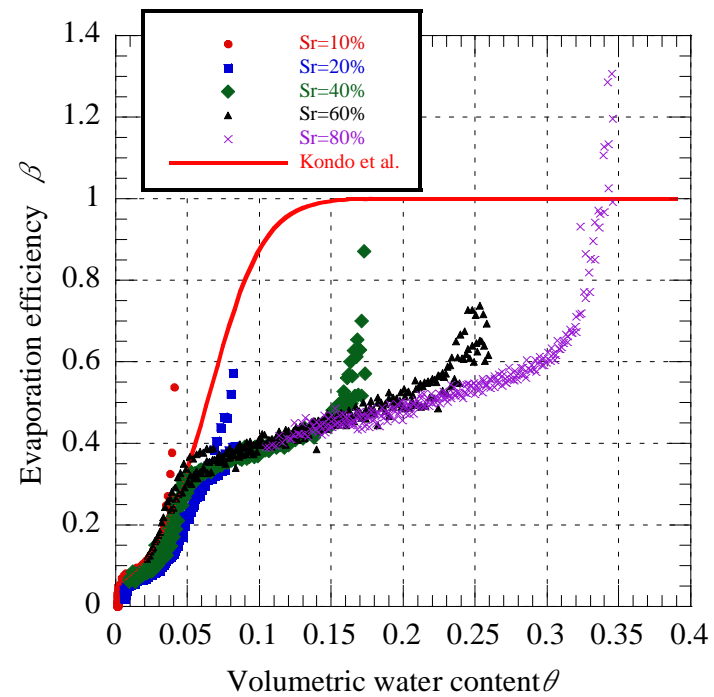

Figure 5. Experimental results of $\theta$ and $\beta$ relation (without the moisture sensors)

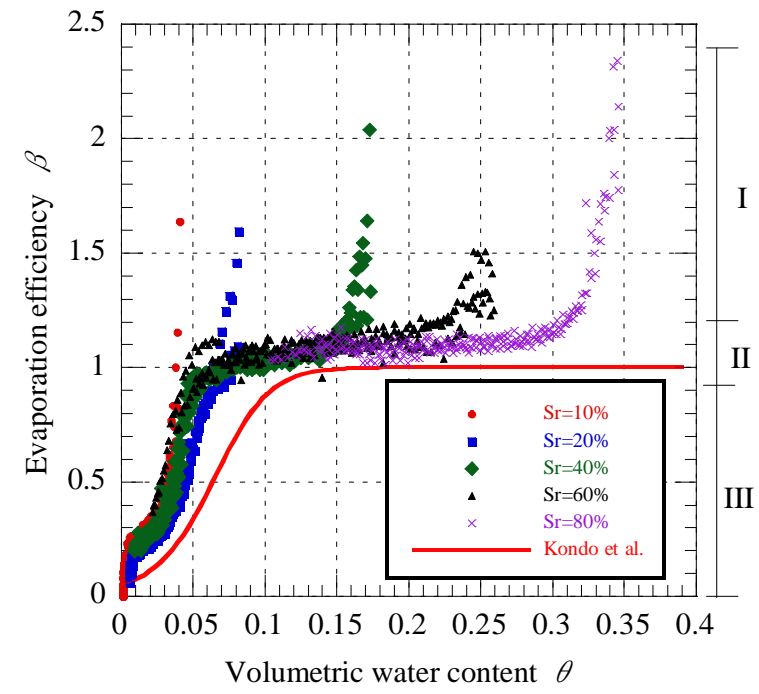

Figure 6. Experimental results of $\theta$ and $\beta$ relation (Using $g_{\text {a,water }}$ 